\title{
Digital discretion and public administration in Africa: Implications for the use of artificial intelligence
}

\author{
Working paper
}

The final, open access version of this article is available here:

Plantinga, P. (2022). Digital discretion and public administration in Africa: Implications for the use of artificial intelligence. Information Development.

https://doi.org/10.1177/02666669221117526

Paul Plantinga, Human Sciences Research Council

pplantinga@hsrc.ac.za

\begin{abstract}
African public administrations are in an especially difficult position with respect to the adoption of artificial intelligence (AI), both in how they harness its benefits but also in managing potential harms. Through a systematic narrative review of previous research, this paper synthesises findings from previous digital government implementations on the African continent, and considers the implications for AI use. Four considerations emerge as relevant: Integrity of recommendations provided by decision-support systems, including how they are influenced by local organisational practices and the reliability of underlying infrastructures; Inclusive decisionmaking that balances the (assumed) objectivity of data-driven algorithms and the influence of different stakeholder groups; Exception and accountability in how digital and AI platforms are funded, developed, implemented and used; and a Complete understanding of people and events through the integration of traditionally dispersed data sources and systems, and how policy actors seek to mitigate the risks associated with this aspiration.
\end{abstract}

Keywords: Public administration, artificial intelligence, Africa, digital, government

\section{Introduction}

Recent technical progress around machine learning (ML), as a prominent sub-field of artificial intelligence (AI), has reignited interest in automated or algorithmic decision-making, including its potential to transform the public service (Araya, 2019). Most automation in current public sector information technology (IT) systems involves making a decision or recommendation based on the application of fixed rules to an analysis of a limited number of variables. ML is different from this largely human-configured automation in that the set of rules (or algorithm) is generated by a computer which considers a much larger amount of data and variables than a human could ever interpret and programme. Moreover, the algorithm can automatically adjust as 
new data is received. In this way ML introduces a new, meta-level of automation into digital government which has important implications for transparency, fairness and accountability in public planning and administrative decision-making (Bullock et al., 2020; Kuziemski and Misuraca, 2020; Zuiderwijk et al., 2021).

With the shift in design, configuration and operation of digital government platforms to higher levels of automation and technical complexity, control and discretion are becoming concentrated in an increasingly elite community of platform companies and 'system-level bureaucrats' responsible for managing data inputs and designing the classification or prediction algorithms (Bovens and Zouridis, 2002). As a result, emerging data-driven applications are raising new questions about the conflation of policy formulation with systems design in these exclusive spaces; but also intensifying concerns about the epistemic dependence and policy alienation of public officials (Van den Hoven, 1998; Tummers et al., 2009). For the recipients of public services, especially those with limited ability or resources to influence system-level activities, these changes can have significant implications for their access to and experience of public services, and the potential for administrative justice (Eubanks, 2018; Sutherland et al., 2019; Razzano, 2020; Raso, 2021).

For African governments and users of public services, the potential risk in these shifts is especially severe for a number of reasons: First, many states are unable to assemble sufficient policy and administrative capacity or influence to mitigate the challenges posed by emerging technologies and global platform companies (Heeks et al., 2021). Second, many governments have become dependent on external technical skills, due to high levels of contracting to the private sector for service delivery functions (Brunette et al., 2019) or because of a dependence on international donor funding and programming (Goldsmith, 2001). Finally, the mainly imported information systems used by governments on the continent are more likely to experience failure due to a mismatch with local infrastructure, capabilities and organisational environments (Berman and Tettey, 2001).

The likelihood, therefore, of public officials in African countries being able to meaningfully engage with the opportunities and risks of AI is low. Whilst this can contribute to an erosion of responsibility and accountability amongst officials, with the potential for longer term damage to the effectiveness of the public service, there is also the more immediate possibility of direct harm to marginalised populations using these technologies, such as through the misuse of personal data (for example, see Torkelson, 2017).

Nonetheless, governments continue to seek opportunities around the use of AI, to address service delivery challenges but also to position themselves (and their local ecosystem) as early adopters in the field. And so the policy response in many parts of the continent is aiming at a 'responsible' approach to the implementation of AI, often building on a platform of data protection legislation enacted in several countries (Gwagwa et al., 2021). 
Whether and how these emerging initiatives translate into a public service that exercises agency on AI, and if this is likely to result in public benefit is a key concern. Importantly, though, the adoption of AI by civil servants is going to be shaped by decades of African experience with existing information and decision-support systems, often in niche applications - from the medical expert systems of the 1980s (Forster, 1992), to established algorithms for calculating unemployment benefits (Horn, 2021) and 30 years of digitalisation at Ghana's customs authority (Addo, 2021) - as well as wider e-government and statistical or open data programmes. In response, this paper aims to synthesise observations from previous digital implementations in African public administrations and considers the implications for AI adoption on the continent. Before doing so, the next section explores digital discretion broadly, its relationship to administrative justice and the emerging role of AI.

\section{Digital discretion, policy alienation and administrative justice}

Proponents of digital and data-driven decision-making see an opportunity for a value shift in public administration, away from procedure-focused indifference and delays to consumeroriented personalisation and efficiency. The reality of information technology (IT) adoption in the public sector has revealed a more complex mix of outcomes that affect the realisation of a diversity of public service values (Busch and Henriksen, 2018; Hood, 1991).

Public officials who use or mediate access to digital tools are central to these outcomes as they ignore, defer to or appropriate decision-support systems (Snow, 2021). The global surveys and indices of e-government, 'digital government reform' and digital inclusion provide limited data or guidance on assessing public official use and attitudes towards technology (for example, see OECD, 2020; UN DESA, 2020; UNESCO, n.d.). Nonetheless, as part of these reports' broader commentary as well as through more targeted country or agency-level studies we are able to get a sense of what civil servants think of digital government and how it influences administrative decision-making (for example, see Baldwin et al., 2012; Antón et al., 2013; Tummers et al., 2009).

Two observations are prominent. First, public officials expect change to happen when using technology, but in a multitude of possible directions; some positive, such as stronger relationships with the public, and others negative, such as information overload (Baldwin et al., 2012; Antón et al., 2013; Tummers et al., 2009). Second, the motivation or intention of public officials to use digital services is influenced by a range of personal factors, including their experience with the technology (Antón et al., 2013) but also drivers in the wider institutional environment. As suggested in OECD Digital Government Index (2020) commentary, the sustainable adoption of digital government reforms in member countries depends on the translation of higher-level policies into formal roles and responsibilities for coordinating the implementation of public sector IT and data initiatives. Similarly, the UN E-Government Survey, which tracks the presence of institutional factors for enabling e-governance practices, such as legal frameworks and guidelines for public officials, notes that that the 
"success of e-government initiatives is largely contingent upon the values that prevail in public administration as a whole and among distinct public entities

and individual staff members. The ethos of a Government and the values promoted by individual institutions determine how interaction with the public is perceived and guide the way ICT is integrated to mediate that relationship" (UN DESA, 2020: 137).

This means that public officials are likely to resist the use of services that are in conflict with the prevailing values. In fact, as noted earlier, a 'shift' in bureaucratic values is seen to be a core enabler and goal of digitalisation initiatives, with implications for a range of related issues, such the principles and rules by which government goes about the procurement of technology (Wilkening et al., 2021). But what are these prevailing values, how are they related to digital technology and what do they mean for service outcomes?

The anticipated outcomes from public sector use of information systems may be rooted in distinct and possibly contradictory value concepts: as examples, technology can help reveal the reasoning behind government actions and thereby enhance political legitimacy (a democratic public value), or it can enable faster decision-making and increased efficiency (a professional public service value), or it can be used to enforce adherence to rules and procedures for fair and uniform decision-making (an ethical public service value) (Busch and Henriksen, 2018).

Ultimately these values form the basis on which citizens and public officials assess the adequacy of digitally-enabled decisions (Raso, 2021). In the case of AI and algorithmic decision-making generally, there are emerging findings from surveys which point to a more general sense of acceptability without providing details on what values are being considered: Data from Switzerland suggests that there are low levels of public trust in the recommendations made by online algorithms (Latzer et al., 2020). In the United States, public acceptance of computer algorithms making decisions related to job applications and personal finance is only about $31 \%$ (Smith, 2018). A nationally representative study in the Netherlands is more positive, with AI being seen as on par or better than human experts when it comes to decisions about public health and justice (Araujo et al., 2020). Limited information is available on how public officials perceive the value of AI, with most focusing on executive-level views related to priority application areas and organisational readiness (for example, see Criado et al., 2021).

Underlying these trends we should expect substantial nuance in how trust is constructed or evolves. For the public service, we have a particular interest in AI's relationship to administrative justice; what form it takes and how it may be realised in different organizational settings (Heeks and Shekhar, 2019; Sutherland et al., 2019; Raso, 2021). The specific role expectations of public officials as well as their professional background and membership intersect with the digitally-delimited decision options designed into digital services by external architects, which can lead to value or ethics conflicts (Hood, 1991; Busch and Henriksen, 2018; Raso, 2021). 
Of broader concern is when the digital 'curtailment' of frontline policy discretion (Buffat, 2015) leads to work alienation (Tummers et al., 2009) and even a descent into thoughtlessness (McQuillan, 2019). Understanding how this occurs as well as possible sites of resistance and agency by public officials, requires a deeper exploration of the genealogy of digital technology use and the contingent stability around what currently works (Gray, 2014). Even where emerging data-driven technologies such as ML present opportunities for change, the potential for a shift in priorities and values of public officials is moderated by the acceptability of decisions in each context; but also the inertia of layers of decade-old data processing and code-driven decisionmaking tools on which AI and ML are built; supported by a network of frontline workers, programmers, infrastructure and databases (Raso, 2021).

Directing 'digital transformation' in the face of this inertia is the subject of various public sector guidelines and courses (for example, see Teaching Public Service in the Digital Age, n.d.). Ensuring broad buy-in to the transformation process is often argued to require participatory and user-centred design methods. For the OECD, involving end users and stakeholders, including government officials and civil society, in digital government reforms can enhance the legitimacy of decisions, but these practices are not widely adopted (2020: 7). In reality, most system development projects in developing countries fall far short of what many scholars feel is appropriate for public interest platforms, especially given the power imbalances and likelihood of further marginalisation of vulnerable groups (Avgerou, 2008). Therefore, whilst there are calls on designers and developers to embed ethical data and AI practices in their work (for examples, see DSCI 2021; UK Government, 2021), these mainly localised attempts at encouraging the codesign of AI solutions - and preventing harm - do not take into account the wider sociotechnical configuration in which system development takes place (Donia and Shaw 2021).

There is also limited consideration of the unique position and responsibility that public officials occupy as both user and mediator of technology-enabled service delivery. As Van den Hoven argued in 1998, systems developers need to take into account three responsibilities when designing platforms for civil servants: task responsibility (as typically outlined in the contract), negative task responsibility (ensuring that no harm is brought about to employees and citizens in performing the task), and also meta-task responsibility (ensure that the user can take his or her responsibilities). In practice though,

"...this will only be possible in a climate of open discussion about design and development issues with a seriousness that used to be associated with political deliberation about the common good in the pre-computer era" (1998: 107-

108).

Here we see an argument for participation that goes beyond design-for-use, to recognise how epistemic empowerment and enslavement through technology are intertwined and need to be addressed as part of a politically sensitive design process. 


\section{Analytical framework and method}

Of course, what the movement around AI and these considerations mean for African public administrations is not clear. Drawing on our experience with other digital and data-driven technologies we may look to develop public sector guidelines on the use of AI in specific sectors, or for how AI should be procured (for example, see UK Government, 2020). However, we will also need to ask more fundamental questions about the way in which AI is embedded within the broader digital and data environment; the mechanisms by which it is likely to enable, curtail or alienate public officials in their delivery of public services; and the expected impact on administrative outcomes.

The following sections present findings from a systematic narrative review of research on digital discretion, e-government and AI from African countries to better understand how AI is, or could be, adopted within existing data and digital environments, and how it may influence the dynamics of public service and its outcomes.

The recent growth in review-type analysis in the information systems field has been supported by calls since the early 2000s for more attention to evidence synthesis as a standalone research approach. Whilst the nature of synthesis has specialised across a range of methods - from narrative to systematic and umbrella reviews - the objectives are similar: to understand the breadth of research in a field, integrate evidence on the effectiveness of interventions, and to develop theories or conceptual background for subsequent research (Paré et al. 2015). As public sector use of AI is an emerging area, there is little guidance on where further study or policy interventions are needed, especially in developing countries. To address this need, a broad synthesis of the African experience with digital discretion can provide a starting point for more in-depth investigation.

The review process involved four broad steps: (1) A starting framework was developed based on an initial set of 'pearl' articles that highlighted key terms and conceptual categories related to digital discretion globally, many of which were discussed in the previous section; (2) A search string was developed using the identified terms, tested and run on the Scopus database to identify articles relevant to digital discretion on the African continent, supplemented by more targeted searches as themes emerged; (3) These articles were screened, grouped and filtered using title, abstract, year of publication and citations to only include those most relevant; (4) Following an in-depth review and synthesis of observations from the included articles, the starting framework was 'fused' with new concepts identified in these studies (Hay, 2011).

The final framework is outlined in the figure below, which highlights the broad conceptual categories resulting from adjustments to the initial framework and integration with the findings from the final review. Perhaps most significant is the addition of a mediating layer of AI 'considerations' which captures the more specific issues emerging from Africa-specific material. These include: 
- Integrity of recommendations - provided by decision-support systems, including how they are influenced by local organisational practices and the reliability of underlying infrastructures.

- Inclusive decision-making - that balances the (assumed) objectivity of data-driven algorithms and the influence of different stakeholder groups.

- Exception and accountability - in how digital and AI platforms are funded, developed, implemented and used.

- Complete understanding - of people and events through the integration of traditionally dispersed data sources and systems, and how policy actors seek to mitigate the risks associated with this aspiration.

These considerations arise at the intersection of at least three influences: experience with previous digital or e-government implementations, emerging digital and AI-specific principles, and public administration values which may be particular to the region or country. The considerations also appear to be relevant to public officials' experience of policy meaning(lessness), policy power(lessness), role clarity (or conflict), curtailment or enablement and ultimately, the realisation of service outcomes and administrative justice in its different forms.

This main objective of this synthesis is to map out key conceptual categories, and so the directional arrows are only indicative of potential relationships for further research. In the following sections, these concepts are discussed in more detail, through the lens of the four considerations introduced above. 
Public officials' experience: e.g. Policy meaning(lessness), policy power(lessness), role clarity (and conflicts), curtailment and enablement (Tummers et al., 2009; Buffat, 2015)
Influences

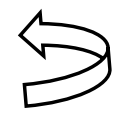

Realises
Service delivery outcomes and administrative justice: e.g. Structural, procedural, instrumental/ substantive (Heeks and Shekhar, 2019; Sutherland et al., 2019; Raso, 2021)

Considerations for AI use in Africa's public service: Integrity of recommendations, Inclusive decision-making, Exception and accountability, Complete understanding (see sections below)

Responsible digital and AI
principles: e.g. fairness,
accountability, transparency,
privacy, equity, multi-
stakeholderism (UNESCO, $\begin{aligned} & \begin{array}{l}\text { Experiences with } \\ \text { implementation of } \\ \text { digital discretion in } \\ \text { public sector: e.g. } \\ \text { 2021; OECD, 2019a; }\end{array} \\ & \text { reliability, accuracy, } \\ & \text { accessibility (see sections } \\ & \text { below) }\end{aligned}$

Public administration values and principles: e.g. ethical, democratic, professional, relational (Hood, 1991; Busch and Henriksen, 2018)

\section{Figure 1 Framework for exploring AI adoption and impact in the public service}

\section{Integrity of recommendations}

The trustworthiness of administrative decision-making enabled by AI is central to ensuring its legitimacy as a tool that can be used in public service environments. If civil servants working with AI-based applications or the citizens affected by decisions do not believe recommendations are reliable and fair, or cannot understand how a decision is reached, then they are unlikely to trust these systems (OECD, 2019a; UNESCO, 2021).

In general, information technology is seen to help public administrations reveal the reasoning behind government actions (and thereby enhance political legitimacy, a democratic public value); but also enforce adherence to rules and procedures (enabling fair and uniform decisionmaking, an ethical public service value). However, research on this topic suggests outcomes are more variable, with the possibility that the use of technology exacerbates discrimination through uneven access and that it can obscure processes (Bannister and Connolly 2014; Busch and Henriksen, 2018). Adding to this, the relatively opaque character of ML algorithms, along with well-documented cases of bias across the ML learning life cycle, have focused public and policy attention on the lack of transparency, explainability and fairness of many AI-based applications (OECD, 2019a; UNESCO, 2021). In African contexts, the integrity and trustworthiness of 
decision-making supported by digital technologies and AI is affected by a number of underlying factors discussed below.

\section{Working practices}

Perhaps most fundamental is the mismatch between values and decision-making models embedded in (mostly) imported technology platforms and those of the local context (Berman and Tettey, 2001; Mensah et al., 2020). Empirical findings from several studies highlight how egovernment projects have not been supported by, as a Malawian study describes, appropriate "administrative structure, processes, decision-making structures, or procedures" and are therefore in conflict with "the way people work" leading to low levels of adoption and motivation to use (Ziba and Kang, 2020: 369-370). In response, much of the focus tends to be on top-down responses that can bring civil servants into line with the platform-designed processes; such as through executive mandates and strategies (Apleni and Smuts, 2020; Mensah et al., 2020; Ziba and Kang, 2020), as well as by enforcing standards and standard operating procedures (Kanga'a et al., 2016: 680).

Unfortunately, the 'way people work' in many African public administrations tends to involve patronage and corruption of various forms, issues which affect the consistency and fairness of decision-making and which are not easily addressed by digital solutions. Deploying information technology to address corruption is often not successful because, in these environments, "systems are inefficient, administrative rationalities different, and enforcement structures generally weak" (Addo, 2021: 109). But it is also because information technology can amplify or create alternative opportunities for corruption, potentially of a much larger scale than the petty corruption prevalent in many African states (Donovan, 2015; Mutungi et al., 2019; Addo, 2021). In fact, the changes or disruption to roles associated with information technology implementation is itself argued to lead to corruption (Elgohary and Abdelazyz, 2020). The integrity of digital systems is further eroded by regular security breaches; and the centralisation of biometric or identity data in national repositories increases the reward for external hackers, whilst creating almost 'infinite' opportunities for internal official misuse of personal data (Breckenridge, 2005: 281). Whilst digital fraud in public systems is also prevalent in most other countries (Anders, 2015; Busch and Henriksen, 2018), African states tend to lack the skills needed to effectively counter these threats (Barata and Cain, 2001).

\section{Technical and human capabilities}

The integrity of decision-support systems in African states is affected by a range of other wellknown technical issues including, amongst others, uneven access to connectivity and the unreliability of information systems. Unreliability is often caused by unstable electricity supplies but is also the result of limited system support skills (Kanga'a et al., 2016; Ziba and Kang, 2020; Forster, 1992). Public officials attempt to mitigate these issues through a variety of responses. In the case of a Kenyan electronic medical record (EMR) implementation, it became necessary to 
maintain a double-entry of information in both paper and digital forms so that services can be provided consistently, adding to the data management workload (Kanga'a et al., 2016: 681). These issues have deeper implications for officials' attitudes to computing systems, beyond just increased frustration and workloads. Recounting a Liberian example, Mensah et al. (2020) describe how system downtimes leads to inconsistencies between physical forms and virtual databases, the outputs of which are then rejected by officials and trust in the system is eroded.

Ultimately, to effectively use digital and data-driven tools in decision-making, sufficient capabilities need to exist amongst front-line officials for interpreting data and data-based recommendations, for being able to explain how decisions are arrived at, and to take responsibility for the impact of the decisions. In examining the deployment of numerous medical expert systems in developing countries during the 1980s, Forster argued that

"the user must understand the basic reasoning of the system and be given the
ultimate responsibility to challenge its output ... If the burden of accountability
lies with the system builder, the user must be skilled enough to question the
assumptions, logic and outcomes of the system"(1992: 22).

However, technology and data-related capacities, especially around more complex needs, are often lacking. For example, in a baseline analysis for an international donor's 'evidence for action' programme in public health the researchers found that the collection and use of data for day-to-day decision making across six African countries appears to be quite widely practiced, but the wider, strategic use of data appears to be a challenge (Nove et al., 2014).

Adding new technologies to work practices can increase access to relevant data, but also leads to information overload for officials, affecting their perceived efficiency and effectiveness (Elgohary and Abdelazyz, 2020; Barata and Cain, 2001: 255). A study of health information system adoption in two tertiary healthcare facilities in South Africa found that the broad, nontargeted adoption of computerised activities adds to workload for nurses, taking time away from

patients - and so the researchers' recommendation is to more carefully target specific work flows for digitalisation (Cline and Luiz, 2013).

\section{Transparency and evidence of what works}

There has been some recognition that the opaque character of AI is making it difficult to understand how decisions are reached or to assess whether an application is operating as expected. At least since the early 1990s, scholars have argued against the deployment of black box expert systems for disease diagnosis in Africa and other developing countries, suggesting that, where technically feasible, "the steps between symptom history and therapy recommendation must be transparent and open to critique and examination by the user" (Forster, 1992: 20). A starting point is to ask whether extensive data collection and complex models are needed in the first place (Forster, 1992; Rudin, 2019). In addition, there is now an established network of researchers, practitioners and policy actors working on methods and tools to support 
fair, transparent and 'explainable' AI; such as for model and bias analysis across the ML pipeline (for example, Google's What-If Tool and IBM's AI Fairness 360). There are also process frameworks being developed for open benchmarking and evaluation of AI technologies (for example, the ITU-WHO Focus Group on Artificial Intelligence for Health), and calls for empirical evidence to demonstrate the safety and efficacy of these technologies - which is critical for their introduction into certain sectors (for example, see Seneviratne et al., 2020).

When all of the above considerations are applied to possible AI implementation - with expected changes to organisational decision-making and roles, additional demands on existing digital infrastructure, new types of sensitive data use and growing adoption of sophisticated data processing - it is clear that the integrity of decision-making supported by AI will depend on a substantial investment in individual and organisational processes and capabilities.

\section{Inclusive decision-making}

The effectiveness and legitimacy of digital government does also depend on a broader set of institutional capabilities, one of which is ensuring meaningful involvement of diverse stakeholders and affected individuals in shaping the use of technology (Busch and Henriksen, 2018). As a more recent example, the values and principles espoused in the UNESCO recommendation on AI note that diversity and inclusion "should be ensured throughout the life cycle of AI systems ... by promoting active participation of all individuals or groups" (2021: 7) and calls for "inclusive public oversight" over the technology's adoption (2021: 10).

\section{Decentralisation}

How participation takes place depends on the institutional arrangements within which technology implementation and technology-mediated decision making take place. The studies from the African continent reviewed in this paper describe quite durable hierarchies anchored in a strong central authority. Earlier commentary on the use of technology in public service organisations went as far as suggesting that there is a fundamental conflict between African states' relatively centralised decision-making controlled by generalist administrators, and the computer-enabled algorithmic model of organisational control imported from Western contexts which presumes the "social acceptance of diverse forms of expert knowledge" (Berman and Tettey, 2001: 3). Endorsing this view, a study of front-line healthcare workers in a number of Africa countries found that "staff's ability to say no to senior staff and colleagues for demands/decisions not supported by evidence was relatively low" (Nove et al., 2014: 105). An emphasis on hierarchy and central authority is evident in similar e-governance research where the focus tends to be on reducing variation between centrally defined policies and their implementation by street-level bureaucrats, and how high-level policies and standards may be incorporated into the design of systems (Barata and Cain, 2001; Reddick et al., 2011). Whilst the use of technology to enforce objectivity and consistency in front-line decision-making has demonstrated value in the delivery of critical welfare services, it does raise a broader question 
about whether there has simply been a redistribution of subjectivity (and corruption, discussed above) to central actors, and an increase in system fragility by creating a central point of failure (as discussed below) (Donovan, 2015).

The same dynamics are reflected at a macro level, between international, national and subnational spheres of governance, where technology is implicated in a tension between the benefits of decentralisation (especially around revenue raising and/ or spending) and a risk that decentralisation creates multiple centres of power (Barata and Cain, 2001; Ochara, 2010). For central officials, digital government provides an opportunity to more effectively monitor and assert disciplinary power over local government, especially through data-driven performance management and fiscal allocation. This 'managerial' approach to inter-governmental relations and public administration supported by digital technologies seems to be at odds with a narrative supporting decentralisation as a way to enable more innovative, open and participatory local policy processes (Ochara, 2010). In the case of relatively powerful city governments, especially, their capture of local data flows and participation in global city networks and knowledge exchanges is an increasingly important influence on policy decision-making (Baud et al., 2014), but is likely to heighten conflicts with national actors.

\section{Primacy of the model}

Much of the ability and authority of central policy officials is derived from the technical complexity and 'objective' authority of the systems or algorithms they employ, which presents a conundrum for what are meant to be participatory planning processes. As a case study covering two South African cities shows, by using a novel GIS-based modelling approach - to prioritise the allocation of facilities for informal settlements - planning officials were able to "reduce political pressure on location choices" (Baud et al., 2014: 506). However, it seems the source and type of political pressure matters: the same study highlights how "input from poorer communities is limited" because of a lack of access to public media and dysfunctional ward representation. As a result, information and inputs to planning tools tends to favour more affluent groups. Yet the authors recognise that stronger engagement with all affected groups would help to address concerns about the assumed validity of data used in GIS modelling (Baud et al., 2014: 507).

Perhaps the most significant practice of data collection to support governance processes is the national identity register, and on the African continent this platform is increasingly enabled by biometric technology (Breckenridge, 2021). From a global perspective, AI-enabled technologies are transforming how biometric collection and processing are taking place, which has significant implications for:

- The way in which data is collected - from an in-person exchange at a government office to the harvesting of camera, social media or mobile phone registration data; 
- The type of data collected - from the relatively simple structural representation of a fingerprint to complex profiling based on data related to voice, gait, face and behaviour;

- How consent is obtained - from a public official facilitating understanding and consent; to continuous, technology-driven monitoring and notification (at most); and

- Nature of identification - from a named-person to an anonymous, behavioural signature or trace (Heller, 2013; Eaves and Rachid, 2020).

In Africa, documentary forms of government have, until recently, continued in many postcolonial states, and involve writing and/ or interaction with civil servants in physical spaces. AIenabled biometric registration and transacting, in contrast, is remote and involuntary, "answering questions about identification, location, and timing without the active participation, or the knowledge of, the subject" (Breckenridge, 2021). Through a "radically simplified claim about the presence and implied consent ... [the technology] works to control the agency of governed subject and the bureaucratic agent by requiring live biometric data from both parties for every transaction" (Breckenridge, 2021). The increasingly instantaneous centralisation of data management in national systems tends to "disempower local officials, who have limited rights to edit records, or change the rules embedded in the database" (Breckenridge, 2005: 281). Moreover, the convergence of a broader set of technologies, including blockchain, around a biometric assemblage reinforces the immutable nature of envisaged identification systems (NOID, 2019).

The simplification and reduction of information associated with digital projects, in which contextual meta-data is often not created or is lost, means that data can become meaningless (Barata and Cain 2001: 255). In reducing contextual information to a single classification or recommendation, intelligent systems are creating an 'informational void' (Breckenridge, 2021); erasing much of the opportunity and story that helps people to explain their case, and so any opportunity for consideration and empathy - as key public service values in many contexts - by local officials becomes lost.

\section{Re-intermediation}

The remote data collection and control offered by digital government, biometric technology and AI enable quite extensive physical disintermediation, which is often central to reducing uncertainty around service delivery. For example, Addo (2021) notes that eliminating physical interaction in Ghana's customs office 'long room' was key to reducing corruption. By digitalising customs activities, whilst outsourcing critical classification and valuation functions to private companies, the customs authority was able to diminish "levels of face-to-face interactions and disintermediated customs bureaucrats from key revenue-generation steps" that feed corrupt activity (Addo 2021: 106). Similarly, in a study of Egyptian local government managers involved in e-government implementation, changes to administrative interaction and discretion - including a reduction in manual processes - are associated with lower variation in 
the implementation of policies by street-level bureaucrats, reduced contact by employees with citizens, and greater accuracy of decisions by employees (Reddick et al., 2011).

In contrast with these observations are studies highlighting the importance of relational processes for supporting the diffusion and use of e-government services (Twinomurinzi et al., 2012). Research describes various forms of re-intermediation in African countries involving group interaction with e-government applications; such as via telecentres, shared phones and assisted use of online services (Heeks, 2002). The same applies to how civil servants support each other with the use of new technology, such as through "forums where peers can engage and discuss issues" affecting use of an electronic health system in Kenya (Kanga'a et al., 2016: 683). Groupmediated adoption of technology is especially important to local government and urban contexts, where physical proximity enables tacit knowledge exchange, more meaningful participation in policy processes and, even, the co-design or co-production of services (Biljohn \& Lues, 2020).

This links with the idea of ubuntu and 'spirit of community' - interpreted as democratic governance enabled by a transparency of actors and roles - which support deliberative processes in 'negotiated spaces', and through which marginalised people can develop stronger forms of citizenship (Baud et al., 2014: 502). In South Africa, the setup of an open and community-based data initiative as an entry point for engagement and knowledge exchange helps to shift power relations related to planning activities. This type of initiative aims to be a counter to the extractive 'datafication' of cities which has often resulted in limited or unjust outcomes for already marginalised groups (Sutherland et al., 2019).

\section{Exception and accountability}

Through its central role in a "fourth industrial revolution" (Schwab, 2016; Caruso, 2018) and because of its relative novelty and technological complexity, AI tends to have an exceptional character. This portrayal of AI has important implications for how policy actors engage with a technology that is already impacting daily life, but is also in many respects science fiction. Unfortunately for today's public officials, digital advances and innovation generally are seen to be incompatible with government bureaucracy in its traditional form and so globally, but also in many African states, there is pressure to establish alternative organisational forms, processes and roles for public officials to be able to harness emerging technological opportunities and to be able to respond to the complexity of current developmental challenges (OECD, 2019b; van der Wal, 2017; Vivona et al., 2020).

\section{Outsourced expertise}

African governments are already unusually dependent on external actors for the delivery of public services, whether international donors or the private sector (for example, see Brunette et al., 2019). Digital technology has somewhat naturally been transferred to recipient countries through these channels - consultants, IT vendors, donor agencies and Western-trained civil 
servants (Heeks, 2002) - often as a component or extension of wider new public management (NPM)-oriented reform programmes. Although this externally-led approach is often viewed as necessary for accelerating the pace and quality service delivery, governments may also be outsourcing to separate themselves from the politics of planning processes or to provide an alternative, more trusted interface for accessing services (Addo, 2021).

The experience of African public officials is that (mainly international) donor representatives are very influential in policy decision-making (Ochara, 2010). As a commentary on financial management systems observes, a donor focus on outcomes rather than processes and practices can have negative consequences, including in the development of parallel systems (Barata and Cain, 2001: 254). In an analysis of e-government adoption in Malawi, there is awareness of an "over-reliance on donors" (Ziba and Kang, 2020: 370-371). Similarly, many of the e-government projects in Liberia have been funded by agencies such as USAID and implemented by consultants, with many senior IT officials concerned about sustainability of projects that do not have a committed government funding allocation (Mensah et al., 2020).

In urban applications AI has been assimilated seamlessly into the smart city agenda in which

"the technical expertise of the private sector means that their power over local government is strong, and likely to grow, as the 'smart city' discourse requires technical expertise outside local government competencies” (Baud et al., 2014: 507).

Smart cities and AI build on a more established tradition of data-supported town planning in African urban contexts, and for which GIS-based modelling has often involved or depended on private consulting firms. Whilst additional stakeholders have been enrolled in the implementation and use of GIS, such as academic or university partners, residents are usually only engaged via consultation and formal feedback processes that tend to favour more affluent individuals and businesses (Baud, 2014; Odendaal, 2003).

Many African cities and states are not able to effectively design and oversee private sector and donor contracts, probably because of the capacity constraints that led to them outsourcing delivery in the first place. Inevitably this leads to exploitation of officials and, ultimately, the most vulnerable users of public digital systems. The conflation of data-gathering by state and business as part of civil registration, identification or social service delivery presents numerous risks (Breckenridge, 2005: 279), and the recent abuse of personal data by a private firm to siphon money from millions of social grant recipients in South Africa is now well documented (Gaffley, 2021). Given this situation, we need to (re)consider how administrative law may be applied to private sector digital service providers operating in the public sector or in areas of public interest (Razzano, 2020). 


\section{Independent digital units and agencies}

In looking to replicate the agility and responsiveness of the private sector within public sector organisations, several governments globally have sought to establish independent digital service and innovation units (Clarke, 2020; Eaves and McGuire, 2018). These units have some freedom to define their own culture, brand and processes, and create space for policy experimentation. The specific structure and relationship to departments and the political sphere can vary considerably.

As an example from South Africa, whilst the State Information Technology Agency (SITA) has a mandate to provide digital services to national and provincial government departments, a portion of the more exploratory data-specific work has been taken up by the Council for Scientific and Industrial Research (CSIR), which has included development of a national patient registration system for the Department of Health (Chetty, 2015) and a National Policy Data Observatory (CSIR, 2021). In establishing these types of platform initiatives, the CSIR is having to navigate a range of political and delivery challenges, whilst also attracting a critical mass of technical talent. But it is the same concentration of skills that makes it challenging for less digitally-capable departments to take on the platforms or services that have been developed. In addition, lines of accountability for the operation of digital services become blurred beyond the user or sector department. Barata and Cain note that when implementing financial management information systems in sub-Saharan Africa, electronic records can be deleted without the responsible official being aware and so often only the technology developer can trace the authenticity of information. They argue that a "solution is needed that exploits the advantage of increased accessibility to information without sacrificing accountability" (2001: 254). As noted earlier, in Forster's analysis of medical expert systems, users - not developers - must have sufficient understanding of the algorithm to take "ultimate responsibility" for a system output (1992: 22).

\section{Sandboxes, pilot projects and private partnerships}

The emergence of independent agencies or units reflects a broader approach to new technologies or policy areas in which funding is ring-fenced for specific activities, and a legal-organisational space is created for some degree of experimentation. One of the more visible instruments being promoted is the regulatory sandbox which, for AI, allows the technology to be tested in, what the World Economic Forum (WEF) suggests is as "real an environment as possible before being released to the world" (WEF, 2021: 20). The sandbox approach has been implemented or considered in countries as diverse as Sierra Leone, Nigeria, Kenya, Rwanda and South Africa as a way for regulatory officials to engage more directly with the fast-growing fintech industry on the African continent. The Mauritius AI strategy sees the country's Regulatory Sandbox License as a key action for enabling innovation in this field, by supporting activities for which there are "no adequate provisions in the existing regulatory framework" (WGoAI, 2018: 19). In African and other developing countries fintech sandboxes have allowed for the relaxation of certain 
finance sector regulatory requirements - such as on know-your-client (KYC), cash balances and management experience - whilst providing more direct supervision and alternative forms of insurance or protection for customers (Wechsler et al., 2018). Analysis of sandbox implementations in these contexts has highlighted that, whilst they provide a useful opportunity for public officials to grow their understanding of emerging technologies, business models, and the likely impact of a specific product on consumers; they provide more limited insights into the systemic effects associated with the introduction of a growing number of (data-driven) digital services. Further, because sandbox interactions are generally quite intimate environments, unless they are carefully designed to incorporate a broader community of participants along with rules on transparency or disclosure, they are likely to cloud the already opaque character of technology-regulatory relationships (Wechsler et al., 2018).

The myriad incubators and pilot projects related to digital public services in African countries, many of them now incorporating AI, reflect the early stage of these technologies but also a shift towards a more experimental or iterative approach to adoption. Similar to sandboxes, by starting small and working in a lean or agile way, sponsors and users in government departments aim to de-risk their financial commitment and minimise negative outcomes for citizens. In piloting (and scaling), governments may also seek 'investor' partners to share the costs and risks, often using proprietary technologies or implemented under confidential arrangements and in the presence of immature or non-existent regulatory safeguards, all of which has significant implications for transparency and accountability - as is evident with the numerous facial recognition projects on the continent (Mudongo, 2021).

\section{Complete understanding}

At the centre of current AI classification and prediction is the desire to develop a more complete understanding of people's behaviour or future events by collecting vast amounts of data on all possibly relevant attributes. Improving the accuracy of decision-making by combining 'big' data from several sources and then "utilizing intelligence algorithms" to generate more accurate recommendations is typical of a professional value set in digital government (Busch and Henriksen, 2018: 11). In response, many national AI strategies are underpinned by a plan to aggregate or integrate various previously disparate pools of data into, as South Korea suggests, a "Data Dam" made up of public and private data (OECD, 2021: 48). The need for this scale and scope of data centralisation is justified by both the opportunity for machine learning to find hidden patterns in apparently unrelated data, as well as the need to improve algorithm performance by training on large volumes of data.

\section{Data integration to enable AI}

From an African perspective, South Africa's draft National Policy on Data and Cloud similarly aims to 'consolidate' public and private data on an 'integrated data platform', to enhance government planning and enable AI (DCDT, 2021). Egypt's AI strategy notes that the "poor 
integration of databases" makes it difficult to "mine and extract useful knowledge" (NCAI, 2021: 21). Similarly, in Uganda's decentralised statistical system "every department produces statistical information according to their individual organisational goals and needs" with varying motivation to produce data, as well as limited compatibility of standards and systems (Ouma, 2014: 3). Uganda's government therefore "affirmed its support of data sharing arrangements between jurisdictions to enable a better understanding of issues and enhance policy development and evidence-based decision making" to help government agencies "deliver better public services" (Ouma, 2014: 2). A national technology centre was expected to support alignment and development of open data guidelines and data inventories for better communicating data availability (Ouma, 2014: 9).

Integration is associated with a range of benefits (and associated values), from reduced errors, to enhanced transparency, and better collaboration. Both Cape Town (Baud, 2014: 506) and eThekwini (Odendaal, 2003) in South Africa have implemented GIS decision-support tools which provided opportunities officials to link or coordinate planning across line departments and between spheres of government. Meanwhile, the adoption of integrated financial management information systems in Sub-Saharan African countries is seen as critical - especially by international donors - for both improving prioritisation and efficiency, but also for ensuring financial accountability, by enabling easier tracking of transactions across government (Barata and Cain, 2001: 251). In the Ghana customs office case study introduced earlier, the move to a data sharing, 'networked' approach enabled a greater level of automation and disintermediation of front-office officials; and contrasts with the "previous tightly linked sequential flows" of earlier IT systems which were more rigid and less transparent, allowing or requiring officials to intervene at various points and create hold-ups or extract corrupt payments (Addo, 2021: 106).

From Liberia to Egypt and South Africa (Reddick et al., 2011; Apleni and Smuts, 2020; Mensah et al., 2020), government officials and researchers have called for greater levels of integration and collaboration to enable more flexible deployment and orchestration of digital services across agencies and departments, and to provide citizens with a more seamless and user-friendly experience. As an example from Lagos State in Nigeria, Olumoye and Govender (2018) aim to address the "separatism of public services" (2018:2) in the issuing of building development permits - which normally involves endless backward and forward travel between multiple departments and agencies. They aspire to a fourth (and fifth) stage of e-government maturity based on full integration of government interaction "that provides services regardless of the organisational borders, via a single access point" (Olumoye \& Govender, 2018: 2). This integration of digital public services goes beyond connecting virtual data and services to also make links with the physical environment, through both the 'upward' collection of biometric and IoT-sourced data, as well as the 'downward' mechanical actuation of instructions via robotic components. 


\section{Integration governance}

Previous experience with integration efforts on the African continent points to a dependence on wider organisational (re)alignment and integration, capacity building and the attitudes of officials (Baud et al., 2014; Olumoye and Govender, 2018).

For front-line public officials, the centralisation of data and control means that they have more limited ability to influence or query decisions. Biometric and other IoT data collection devices are designed to "resist the editorial or authorial interventions of their owners" (Breckenridge, 2021), and reduce the need for information or data capturing and editing that would normally be performed by local public officials. Whilst centralisation and automated data collection may be useful for reducing variation and corruption, for many civil service roles this can undermine accountability and the potential for establishing trusted relationships with users - a key requirement for the uptake of public health services (Habli et al., 2020).

Inevitably, there are both intra and inter-organisational processes and challenges when it comes to integration, with the potential for both system failures but also broader harms. These governance questions are probably most evident around biometric and identity data. African and various other developing countries are unique in their adoption of centralised national identity systems that increasingly form the basis for accessing public services, often with strong connections to private financial information and credit systems (Breckenridge, 2021). Biometric data and personal digital devices have become the 'primary keys' for linking a previously disparate array of private and state-managed data sources on individuals. For example, in seeking higher levels of assurance on the identity of a customer, the mobile industry body, GSMA, is aiming to connect financial sector KYC processes with mobile phone SIM card registration requirements (Theodorou, 2019).

In addition, donors and aid agencies often establish their own identity platforms or layer them on top of national systems, whilst the outsourcing of various administrative functions to the private sector - such as payment of grants, issuing of passports and registration of businesses - has increased the integration and movement of potentially sensitive data between sectors. As introduced above, in South Africa, a lack of oversight around data sharing related to social grants has led to the large-scale exploitation of vulnerable people (Gaffley, 2021), whilst the adoption of an information system for health records sharing in the country's hospitals elevated concerns amongst staff about increased risks to privacy and confidentiality of data (Cline and Luiz, 2013).

For Breckenridge, "there is almost no official and very little public concern for individual privacy, the probability of data-creep on a large scale, and almost open-ended possibilities for abuse" related to biometric identity systems (2005: 278). Moreover, the extreme parsimony of biometric identification in modern systems, and their almost instantaneous transfer, enables "centralization around a single-point of control (and of failure)" (Breckenridge, 2021, emphasis added). These shifts in data collection and sharing suggest that the governance of data integration 
is experiencing a form of defacto dispersion to a range of actors, very often without the institutionalised input, coordination or oversight that can ensure responsible use.

\section{Implications for AI adoption in Africa's public service}

This paper has sought to understand the ways in which public official decision-making is likely to be influenced by the adoption of AI, and how this in turn may shape the delivery of public services. Of particular concern is how governments and officials on the African continent may navigate a more sustainable approach to using AI that draws on the lessons from previous digital and data implementations.

Much of the region's research on digital platforms and decision-support systems has been concerned with e-government 'readiness' and technology adoption, with influential sectorspecific clusters, such as in public health decision-making and urban planning. This body of work tends to focus on why citizens and public officials resist or embrace technology and the various socio-technical factors that influence the success of systems implementation - from a reliable power supply to training and change management.

Of broader significance are the organisational changes and value shifts in the public service that many proponents of digital technologies and innovation anticipate with the adoption of AI, and which may or may not occur. So, how do front-line public officials (but also system developers and central policy actors) in African governments interpret or understand their role, agency and accountability with respect to digital discretion, and what does this mean for their relationship with $\mathrm{AI}$ and realising public administration values?

It does seem that AI is likely to amplify a number of digital government dynamics, with potentially contradictory effects on public service practice and outcomes. First, the implications of AI for the integrity of decisions, and the nature of trust between citizens and state is ambiguous. For example, whilst AI may enable more accurate decision-making and thereby enhance the legitimacy of administration, its opaque character can undermine confidence in digitally-enabled recommendations and reduce officials' ability to explain how decisions have come about. Moreover, AI implementation in Africa is being layered on top of what are often quite fragile information and data platforms, for which officials' already have limited skills and see as a source of information overload. This could be mitigated by directing AI adoption at specific challenges or workflows. Yet, given the early-stage of most AI implementations there would still be a need for guidance on assessing the accuracy and safety of these applications, as well as some form of independent monitoring and evaluation to support the introduction and removal of products.

A second area of consideration is the influence of AI on democratic values, both in how the technology may support more inclusive public service decision-making but also in how its implementation is governed. AI, in its reductionist form, removes much of the meaning, context and "background of common social causes" which cannot be mathematised (McQuillan, 2020: 
165). By seeking to describe (or ascribe) the innate attributes of individuals (McQuillan, 2020), there is limited space for context and contest by the subjects of automated decisions, whilst frontline officials are confronted with increased 'policy powerlessness' (Tummers et al., 2009). The remote forms of data collection and predictive decision-making supported by AI-enabled biometrics and modelling are therefore likely to disempower local officials by foreclosing alternative decisions and curtailing much of the engagement and empathy regarded as key values in many public administrations.

These trends dovetail with research from Africa's public sector suggesting that digital technologies have mainly been enrolled into processes of centralisation; as a means for reducing variation in policy implementation across fragmented administrations and for reducing petty corruption at a local level. However, the reality is that effective and inclusive use of these technologies often depends on some form of re-intermediation in which networks of people (centrally or at local levels) share experiences, appropriate technologies and encourage adoption. This goes beyond encouraging a user or human-centred approach to AI design which has tended to reinforce an individualised approach and can lead to marginalisation of certain groups (Marcus, 2021). So we may expect - and look to harness - resistance from district and front-line officials contesting the 'primacy' of digital and AI-enabled decision-making and centralised implementation, as well as from cities and city-networks, as clusters of learning develop around the role and use of AI.

As a relatively new technology, we have seen that AI deployment tends to take place outside of core departmental processes or structures, often in the form of pilot projects with private sector partners. The exceptional character of AI, in its futuristic portrayal and in how it is being implemented, means that we should be especially sensitive to issues of accountability and responsibility for both immediate operational and longer-term societal impacts. In Africa, government dependence on the private sector for the introduction of new technologies means that there will be growing pressure on procurement officials to better assess data-oriented and AI services. To fill the gap, certain African states have looked to draw on public research or digital service units. In South Africa, the CSIR's work on a national patient registration system is the type of 'platform enablement' activity that Eaves and McGuire (2018) regard as the 'end-game' to which digital service groups aspire globally. Getting to this point requires significant effort to, amongst others, build political capital and delivery capability. The apparent success of these groups in Africa but also other regions is largely driven by an ability to recruit talented technologists, by providing an opportunity to work on socially-impactful projects "in a unit that defies pejorative stereotypes of government bureaucracy" (Clarke, 2020: 368).

Because of their ability to attract talent and accelerate implementation, intra-governmental digital service units are becoming an important alternative vehicle for introducing new technologies (and processes) in government. In reality, however, it is well known that the acceptance and use of technology by officials can decline once a developer team completes project delivery. As with all new information systems, there is a substantial gap between pilot-stage 'adoption' and 
broader implementation, which requires extensive process redesign, capacity building and sustainable funding (Molinari et al., 2021). Moreover, digital service units tend to operate outside of traditional hierarchies, meaning that accountability for digitally-enabled decisionmaking can become confused between developer team and users.

This points to a broader concern that via pilot projects, special units and private partnerships, AI is coming in to use through a 'state of exception' with "the tendency to escape due process through preemption and justify actions based on correlation rather than causation" (McQuillan, 2015: 568). Underlying this way of working is an assumption that the insights from data (and now AI) are objective, that is: "with enough data, the numbers speak for themselves" (Anderson, 2008). Therefore, thinking about how AI implementation can be embedded in existing values and rights-based frameworks (e.g. country constitutions, public service charters, and international commitments) and legal safeguards (e.g. public procurement and data protection regulations) is critical for its ongoing legitimacy and sustainable adoption on the African continent.

One of the more significant areas in which safeguards are needed is around the governance of large-scale data collection, aggregation and integration which many African AI and data strategies envisage. This integration of data and systems echoes calls for the 'platformisation' of government (O'Reilly, 2011; Eaves and McGuire 2018), as well as the notion of a single access point for services or 'single view' of citizens (for example, see Wiseman, 2017; Barbaschow, 2018). Whilst integration can simplify service access, policy actors in other regions, notably the European Union (EU), have acknowledged that the integration and centralisation of data can undermine citizens' trust in digital services. This is due to, amongst others, concerns that centralised databases become targets for hackers, and that the possibility of re-identification and discrimination is higher when databases are merged (European Parliament, 2019; cc:eGov, 2007). Civil society advocates in the EU and United States have therefore proposed similar responses to these issues, including giving data subjects the legal power to request that data be deleted from a database and pursuing regulations restricting the integration or merging of specific data sources and types (Lynch, 2019: 25). More technical measures to mitigate harms include developing exchange protocols between the data silos of the various government entities, rather than looking to consolidate data on a single database (cc:eGov, 2007: 13); distorting raw biometric data so that it is less reusable (Grijpink, 2008); and exploring AI-based tools that can reduce the need for large-scale data harvesting such as data augmentation, transfer learning and synthetic data sets (Polonetsky and Renieris, 2020).

This paper argues that we may look to draw on Africa's previous experiences and research around digital government and data-supported decision-making to pre-emptively guide the development and adoption of AI in the public service. From the discussion above, it is clear that other parts of the world are dealing with similar issues, and that there should be opportunities to learn from emerging responses. In large part, a sustainable and effective approach will need to involve a more explicit recognition of the role of civil servants in mediating the use and impact 
of AI-enabled services, including the distinct values that they attach to decision-making, whether professional, ethical, democratic, relational or other.

Each of the considerations explored in the sections above will benefit from deeper investigation as AI comes into wider use. But research on AI adoption in Africa's public service may also look more broadly, at the fit between what are mainly internationally developed platforms and local institutional characteristics (Berman and Tettey, 2001). Ultimately, as much of this work acknowledges, these 'technologies of administration' have their origins in a global and regional political economy which can enable the recreation of a less tangible form of colonial power (Breckenridge, 2005; Breckenridge, 2021), and for which a 'structural' response may be necessary (Heeks and Shekhar, 2019).

\section{References}

Addo A (2021) Controlling petty corruption in public administrations of developing countries through digitalization: An opportunity theory informed study of Ghana customs. The Information Society, 37(2): 99-114.

Anders G (2015) The normativity of numbers in practice: technologies of counting, accounting and auditing in Malawi's civil service reform. Social Anthropology, 23(1): 29-41.

Anderson, C (2008) The End of Theory: The Data Deluge Makes the Scientific Method Obsolete. Wired, 23 June. Available at: https://www.wired.com/2008/06/pb-theory/ (Accessed 07 January 2022).

Antón C, Camarero C and San José R (2014) Public Employee Acceptance of New Technological Processes: The case of an internal call centre. Public Management Review, 16(6): 852-875.

Apleni A and Smuts H (2020) An e-Government implementation framework: a developing country case study. Responsible Design, Implementation and Use of Information and Communication Technology, 12067, 15.

Araujo T, Helberger N, Kruikemeier S and De Vreese CH (2020) In AI we trust? Perceptions about automated decision-making by artificial intelligence. AI \& Society, 35(3): 611-623.

Araya D (2019) Artificial Intelligence and the End of Government. Forbes, 4 January. Available at: https://www.forbes.com/sites/danielaraya/2019/01/04/artificial-intelligence-and-the-end-ofgovernment/ (accessed 11 June 2021).

Avgerou C (2008) Information systems in developing countries: a critical research review. Journal of information Technology, 23(3): 133-146.

Baldwin JN, Gauld R and Goldfinch S (2012) What public servants really think of e-government. Public Management Review, 14(1): 105-127. 
Bannister F and Connolly R (2014) ICT, public values and transformative government: A framework and programme for research. Government Information Quarterly, 31(1): 119-128.

Barata K and Cain P (2001) Information, not technology, is essential to accountability: electronic records and public-sector financial management. The Information Society, 17(4): 247-258.

Barbaschow A (2018). e-Estonia: What is all the fuss about? ZDNet, 13 August. Available at: https://www.zdnet.com/article/e-estonia-what-is-all-the-fuss-about/ (accessed 11 November 2021).

Baud ISA, Scott D, Pfeffer K, Sydenstricker-Neto J and Denis E (2014). Digital and spatial knowledge management in urban governance: Emerging issues in India, Brazil, South Africa, and Peru. Habitat International, 44: 501-509.

Berman BJ and Tettey WJ (2001) African states, bureaucratic culture and computer fixes. Public Administration and Development: The International Journal of Management Research and Practice, 21(1): 1-13.

Biljohn MIM and Lues L (2020) Citizen participation, social innovation, and the governance of local government service delivery: findings from South Africa. International Journal of Public Administration, 43(3): 229-241.

Bovens M and Zouridis S (2002) From street-level to system-level bureaucracies: How information and communication technology is transforming administrative discretion and constitutional control. Public Administration Review, 62(2): 174-184.

Breckenridge K (2005) The biometric state: The promise and peril of digital government in the new South Africa. Journal of Southern African Studies, 31(2): 267-282.

Breckenridge K (2021) Documentary government and mathematical identification: On the theoretical significance of African biometric government. In: Identification and Citizenship in Africa (ed SA Dalberto and R Banégas), pp. 49-64. London: Routledge.

Brunette R, Klaaren J and Nqaba P (2019) Reform in the contract state: Embedded directions in public procurement regulation in South Africa. Development Southern Africa, 36(4): 537-554.

Bullock J, Young MM, and Wang YF (2020) Artificial intelligence, bureaucratic form, and discretion in public service. Information Polity, 25(4): 491-506.

Buffat A (2015) Street-level bureaucracy and e-government. Public Management Review, 17(1): 149-161.

Busch PA and Henriksen HZ (2018) Digital discretion: A systematic literature review of ICT and street-level discretion. Information Polity, 23(1): 3-28.

Caruso L (2018) Digital innovation and the fourth industrial revolution: epochal social changes? AI \& Society, 33(3): 379-392. 
cc:eGov (2007) A Handbook for Citizen-centric eGovernment. Version 2.1 December. Available at: https://joinup.ec.europa.eu/sites/default/files/document/2014-12/media1781.pdf (Accessed 09 January 2022).

Chetty, M (2015) Supporting the South African healthcare system with e-health technologies. CSIR Science Scope, 8(2): 34-35.

Clarke A (2020) Digital government units: what are they, and what do they mean for digital era public management renewal? International Public Management Journal, 23(3): 358-379.

Cline GB and Luiz JM (2013) Information technology systems in public sector health facilities in developing countries: the case of South Africa. BMC medical informatics and decision making, 13(1): 1-12.

Criado JI, Sandoval-Almazan R, Valle-Cruz D and Ruvalcaba-Gómez EA (2021) Chief information officers' perceptions about artificial intelligence. First Monday.

CSIR (Council for Scientific and Industrial Research) (2021) Annual Report 2020/2021. Pretoria: Republic of South Africa.

DCDT (Department of Communications and Digital Technologies) (2021) Draft National Policy on Data and Cloud. Pretoria: Republic of South Africa.

Donia J and Shaw J (2021) Co-design and Ethical Artificial Intelligence for Health: Myths and Misconceptions. In: Proceedings of the 2021 AAAI/ACM Conference on AI, Ethics, and Society.

Donovan KP (2015) The biometric imaginary: Bureaucratic technopolitics in post-apartheid welfare. Journal of Southern African Studies, 41(4): 815-833.

DSCI (Data Security Council of India) (2021) Handbook on Data Protection and Privacy for Developers of Artificial Intelligence (AI) in India: Practical Guidelines for Responsible Development of AI. Available at: https://www.dsci.in/content/privacy-handbook-for-aidevelopers (Accessed 23 January 2022).

Eaves D and McGuire B (2018) 2018 State of Digital Transformation. Belfer Center for Science and International Affairs, Harvard Kennedy School, Harvard University. Available at: https://www.belfercenter.org/publication/2018-state-digital-transformation (Accessed 03 December 2021).

Eaves D and Rachid N (2020) Before we rush to adopt facial recognition technology, the public and policy-makers must ensure that the increased surveillance power is not abused. Policy Options, 25 February. Available at: https://policyoptions.irpp.org/magazines/february2020/facial-recognition-technology-requires-checks-and-balances/ (Accessed 03 February 2022).

Elgohary E and Abdelazyz R (2020) The impact of employees' resistance to change on implementing e-government systems: An empirical study in Egypt. The Electronic Journal of Information Systems in Developing Countries, 86(6): e12139. 
Eubanks V (2018) Automating inequality: How high-tech tools profile, police, and punish the poor. New York: St. Martin's Press.

European Parliament (2019) Interoperability between EU border and security information systems. EU Legislation in Progress. Available at:

https://www.europarl.europa.eu/RegData/etudes/BRIE/2018/628267/EPRS_BRI(2018)628267_ EN.pdf (Accessed 12 December 2021).

Forster D (1992) Expert systems in health for developing countries: practice, problems, and potential. Ottawa: IDRC.

Gaffley M (2021) AI and Data in South Africa's Finance Sector: Towards Financial Inclusion. PAN Topical Guides AI \& Data Series 9. Human Sciences Research Council and University of Pretoria.

Goldsmith AA (2001) Foreign aid and statehood in Africa. International organization, 55(1): 123-148.

Gray J (2014) Towards a genealogy of open data. Paper presented at: European Consortium for Political Research (ECPR) General Conference 2014, Glasgow, 3-6 September.

Grijpink JHAM (2008) Trend report on biometrics: Some new insights, experiences and developments. Computer Law and Security Report, 24(3): 261-264.

Gwagwa A, Kachidza P, Siminyu K and Smith M (2021) Responsible artificial intelligence in Sub-Saharan Africa: landscape and general state of play. Artificial Intelligence for Development - Africa. Available at: https://ircai.org/wpcontent/uploads/2021/03/AI4D_Report_Responsible_AI_in_SSA.pdf (accessed 12 November 2021).

Habli I, Lawton T and Porter Z (2020) Artificial intelligence in health care: accountability and safety. Bulletin of the World Health Organization, 98 (4).

Hay, C (2011) Interpreting Interpretivism, Interpreting Interpretations: the New Hermeneutics of Public Administration. Public Administration, 89(1): 167-182.

Heeks R (2002) e-Government in Africa: Promise and practice. Information polity, 7(2, 3): 97114.

Heeks R and Shekhar S (2019) Datafication, development and marginalised urban communities: An applied data justice framework. Information, Communication \& Society, 22(7): 992-1011.

Heeks R, Gomez-Morantes JE, Graham M, Howson K, Mungai P, Nicholson B and Van Belle JP (2021) Digital platforms and institutional voids in developing countries: The case of ride-hailing markets. World Development, 145: 105528.

Heller KJ (2013) 'One Hell of a Killing Machine': Signature Strikes and International Law, Journal of International Criminal Justice 11(1). 
Hood C (1991) A public management for all seasons? Public administration, 69(1): 3-19.

Horn A (2021) South Africa's Unemployment Insurance Fund Benefit Function: A Mathematical Critique. SALDRU Working Paper Series Number 276. Available at:

http://opensaldru.uct.ac.za/handle/11090/1004 (Accessed 03 February 2022)

Kang'a SG, Muthee VM, Liku N, Too D and Puttkammer N (2016) People, Process and Technology: Strategies for Assuring Sustainable Implementation of EMRs at Public-Sector Health Facilities in Kenya. In: AMIA Annual Symposium Proceedings, Vol. 2016, p.677. American Medical Informatics Association.

Kuziemski M and Misuraca G (2020) AI governance in the public sector: Three tales from the frontiers of automated decision-making in democratic settings. Telecommunications policy, 44(6): 101976.

Latzer M, Festic N and Kappeler K (2020) Awareness of Algorithmic Selection and Attitudes in Switzerland. Report 2 from the Project: The Significance of Algorithmic Selection for Everyday Life: The Case of Switzerland. Zurich: University of Zurich. Available at: http://mediachange.ch/research/algosig (Accessed 02 February 2022).

Lynch J (2019) Face Off: Law Enforcement Use of Face Recognition Technology. Electronic Frontier Foundation. Available at: https://www.eff.org/files/2019/05/28/face-off-report.pdf (Accessed 15 November 2021).

Marcus M (2021) Beyond HCD: Do we need a new approach for designing with AI? $U X$ Collective, 9 January. Available at: https://uxdesign.cc/do-we-need-a-new-approach-fordesigning-with-ai-8763c876fad5 (Accessed 03 November 2021).

McQuillan D (2015) Algorithmic states of exception. European Journal of Cultural Studies, 18(4-5): 564-576.

McQuillan D (2019) Non-Facist AI. In: Propositions for Non-Fascist Living: Tentative and Urgent (ed M Hlavajova and W Maas), Utrecht and Cambridge, MA: BAK and MIT Press.

McQuillan, D. (2020). The Political Affinities of AI. In: The Democratization of Artificial Intelligence (ed A Sudmann), pp. 163-174. Bielefeld: transcript-Verlag.

Mensah R, Cater-Steel A and Toleman M (2021) Factors affecting e-government adoption in Liberia: A practitioner perspective. The Electronic Journal of Information Systems in Developing Countries, 87(3): e12161.

Molinari F, van Noordt C, Vaccari L, Pignatelli F and Tangi L (2021) AI Watch. Beyond pilots: sustainable implementation of AI in public services, EUR 30868 EN. Publications Office of the European Union, Luxembourg.

Mudongo O (2021) Re Ntse Re Go Lebile: Computer Vision and AI Surveillance in Africa Work in Progress Version. Research ICT Africa. Available at: 
https://media.africaportal.org/documents/Computer-Vision_Report_WorkInProgress.pdf (Accessed 03 February 2021).

Mutungi F, Baguma R and Janowski T (2019) Towards digital anti-corruption typology for public service delivery. In: Proceedings of the 20th Annual International Conference on Digital Government Research, pp. 484-494, United Arab Emirates: Dubai, June 18-20.

NCAI (The National Council on Artificial Intelligence, Egypt) (2021) Egypt National Artificial Intelligence Strategy. Available at:

https://mcit.gov.eg/en/Publication/Publication_Summary/9283 (Accessed 12 November 2021).

NOID (National Office for Identity Data, Minister of the Interior and Kingdom Relations, The Netherlands) (2019) Technological Developments and Innovation, ID4Africa Presentation. Available at: https://www.id4africa.com/2019_event/presentations/PS4/1-Rhodia-MaasNetherlands.pdf (Accessed 12 November 2021).

Nove A, Hulton L, Martin-Hilber A and Matthews Z (2014) Establishing a baseline to measure change in political will and the use of data for decision-making in maternal and newborn health in six African countries. International journal of gynecology \& obstetrics, 127(1): 102-107.

O’Reilly T (2011) Government as a Platform. Innovations: Technology, Governance, Globalization, 6(1): 13-40.

Ochara NM (2010) Assessing irreversibility of an E-Government project in Kenya: Implication for governance. Government Information Quarterly, 27(1): 89-97.

Odendaal N (2003) Information and communication technology and local governance: Understanding the difference between cities in developed and emerging economies. Computers, environment and urban systems, 27(6): 585-607.

OECD (Organisation for Economic Co-operation and Development) (2019a) Recommendation of the Council on Artificial Intelligence. OECD/LEGAL/0449. Available at: https://legalinstruments.oecd.org/en/instruments/OECD-LEGAL-0449 (Accessed 03 February 2022).

OECD (Organisation for Economic Co-operation and Development) (2019b) Embracing Innovation in Government: Global Trends 2019. Paris: OECD

OECD (Organisation for Economic Co-operation and Development) (2020) Digital Government Index: 2019 results. OECD Public Governance Policy Papers, No. 03. Paris: OECD.

OECD (Organisation for Economic Co-operation and Development) (2021) State of implementation of the OECD AI Principles. Paris: OECD. Available at: https://www.oecdilibrary.org/science-and-technology/state-of-implementation-of-the-oecd-aiprinciples_1cd40c44-en (Accessed 03 February 2022). 
Olumoye MY and Govender I (2018) An empirical investigation of factors influencing integrated e-G overnment implementation in Nigeria: A case of housing and urban development agency. The Electronic Journal of Information Systems in Developing Countries, 84(1): e12012.

Ouma FK (2014) Impediments to interagency statistical information sharing amongst government agencies in Uganda: A G2G adoption. In: 2014 IST-Africa Conference Proceedings, pp. 1-11, 6-9 May.

Paré G, Trudel MC, Jaana M and Kitsiou S (2015) Synthesizing information systems knowledge: A typology of literature reviews. Information \& Management, 52(2): 183-199.

Polonetsky J and Renieris E (2020) Privacy 2020: 10 Privacy Risks and 10 Privacy Enhancing Technologies to Watch in the Next Decade. Future of Privacy Forum. Available at: https://fpf.org/wp-content/uploads/2020/01/FPF_Privacy2020_WhitePaper.pdf (Accessed 08 January 2022).

Raso J (2021) Implementing Digitalization in an Administrative Justice Context. In: Oxford Handbook of Administrative Justice (ed J Tomlinson, R Thomas, M Hertogh and R Kirkham). Oxford: Oxford University Press.

Razzano G (2020) The public-private: a key legal nexus for South Africa's AI future. Research ICT Africa Policy Brief No. 6.

Reddick CG, Abdelsalam HM and Elkadi H (2011) The influence of E-Government on administrative discretion: The case of local governments in Egypt. Public Administration and Development, 31(5): 390-407.

Rudin C (2019) Stop explaining black box machine learning models for high stakes decisions and use interpretable models instead. Nature Machine Intelligence, 1(5): 206-215.

Schwab K (2016) The Fourth Industrial Revolution: what it means, how to respond. World Economic Forum. Available at: https://www.weforum.org/agenda/2016/01/the-fourth-industrialrevolution-what-it-means-and-how-to-respond/ (Accessed 28 January 2022).

Seneviratne MG, Shah NH and Chu L (2020) Bridging the implementation gap of machine learning in healthcare. BMJ Innovations, 6(2).

Smith, A (2018) Public Attitudes Toward Computer Algorithms. Pew Research Centre, 16 November. Available at: https://www.pewresearch.org/internet/2018/11/16/public-attitudestoward-computer-algorithms/ (Accessed 28 January 2022).

Snow T (2021) From satisficing to artificing: The evolution of administrative decision-making in the age of the algorithm. Data \& Policy, 3.

Sutherland C, Mazeka B, Buthelezi S, Khumalo D and Martel P (2019) Making Informal Settlements 'Visible' Through Datafication: A Case Study of Quarry Road West Informal Settlement, Durban, South Africa. Development Informatics Working Paper, (83). 
Teaching Public Service in the Digital Age (n.d.) How David Eaves teaches Unit 8 (part one). Available at: https://www.notion.so/How-David-Eaves-teaches-Unit-8-part-onebea0cc08e9b241c49feb4baecabd583a (Accessed 20 January 2022).

Theodorou Y (2019) Leveraging Mobile to Accelerate Digital Identity Ecosystems: Considerations for Policymakers in Africa. GSMA. ID4Africa, Johannesburg, South Africa. Available at: https://www.id4africa.com/2019/almanac/GSMA-Yiannis-Theodorou.pdf (Accessed 20 January 2022).

Torkelson E (2017) Sophia's Choice: Farm Worker Has to Decide Which of Her Children to Feed. Ground Up, 15 March. Available at: https://www.groundup.org.za/article/sophias-choicefarm-worker-has-decide-which-her-children-feed/ (accessed 15 June 2021).

Tummers L, Bekkers V and Steijn B (2009) Policy alienation of public professionals: Application in a new public management context. Public Management Review, 11(5): 685-706. Twinomurinzi H, Phahlamohlaka J and Byrne E (2012) The small group subtlety of using ICT for participatory governance: A South African experience. Government Information Quarterly, 29(2): 203-211.

UK Government (2021) Ethics, Transparency and Accountability Framework for Automated Decision-Making. Available at: https://www.gov.uk/government/publications/ethicstransparency-and-accountability-framework-for-automated-decision-making (Accessed 20 November 2021).

UK Government (2020) Guidelines for AI Procurement. Available at: https://www.gov.uk/government/publications/guidelines-for-ai-procurement/guidelines-for-aiprocurement (Accessed 20 November 2021).

UN DESA (United Nations Department of Economic and Social Affairs) (2020) E-Government Survey 2020. Available at: https://www.un.org/development/desa/publications/publication/2020united-nations-e-government-survey (Accessed 20 January 2022).

UNESCO (United Nations Educational, Scientific and Cultural Organization) (n.d.) ROAM-X Indicators. Available at: https://en.unesco.org/internet-universality-indicators/roamx-indicators (Accessed 24 January 2022).

UNESCO (United Nations Educational, Scientific and Cultural Organization) (2021) Draft text of the recommendation on the ethics of artificial intelligence. $41 \mathrm{C} / 73$ Annex. Report of the Social and Human Sciences Commission (SHS), 41st session, General Conference. November 22. Paris Available at: https://unesdoc.unesco.org/ark:/48223/pf0000379920.page=14 (Accessed 03 February 2022).

Van den Hoven MJ (1998) Moral responsibility, public office and information technology. In: Public administration in an information age: a handbook (ed IThM Snellen and WBHJ van de Donk), pp.97-112. Amsterdam; Washington, DC: IOS Press. 
van der Wal Z (2017) The 21st century public manager. London: Palgrave.

Vivona R, Demircioglu MA and Raghavan A (2020) Innovation and Innovativeness for the Public Servant of the Future: What, Why, How, Where, and When. In: The Palgrave Handbook of the Public Servant (ed H Sullivan, H Dickinson and H. Henderson), pp.1-22, London: Palgrave.

Wechsler M, Perlman L and Gurung N (2018) The state of regulatory sandboxes in developing countries. Digital Financial Services Observatory. Columbia Institute for Tele-Information. Available at: https://dfsobservatory.com/publication/state-regulatory-sandboxes-developingcountries (Accessed 03 February 2022).

WEF (World Economic Forum) (2021) The AI Governance Journey: Development and Opportunities. Available at: https://www.weforum.org/reports/the-ai-governance-journeydevelopment-and-opportunities (Accessed 03 February 2022).

WGoAI (Working Group on Artificial Intelligence) 2018 Mauritius Artificial Intelligence Strategy. Available at: https://ncb.govmu.org/ncb/strategicplans/MauritiusAIStrategy2018.pdf (Accessed 03 February 2022).

Wilkening M, Nukuna N and Hutt J (2021) Managing the Cultural Challenges of Agile Procurement. In: 2020 State of Digital Transformation (ed D Eaves and L Lombardo), pp.40-45, Ash Center for Democratic Governance and Innovation, Harvard University.

Wiseman J (2017) Improving Service Delivery through Information Integration: Building a Single View of the Citizen. Innovations in Public Service Delivery, (5). Inter-American Development Bank. Available at: https://publications.iadb.org/publications/english/document/Innovations-in-Public-ServiceDelivery-Issue-No-5-Improving-Service-Delivery-through-Information-Integration-Building-aSingle-View-of-the-Citizen.pdf (Accessed 04 January 2022).

Ziba PW and Kang J (2020) Factors affecting the intention to adopt e-government services in Malawi and the role played by donors. Information Development, 36(3): 369-389.

Zuiderwijk A, Chen YC and Salem F (2021) Implications of the use of artificial intelligence in public governance: A systematic literature review and a research agenda. Government Information Quarterly, 101577. 